\title{
A PROPÓSITO DE LAS POESÍAS COMPLETAS DE JOSÉ MORENO VILLA
}

Sería muy cómodo empezar este comentario sobre las Poesías completas $^{1}$ de José Moreno Villa denunciando el olvido en que la obra de este poeta ha caído. Sería cómodo, pero no sería del todo legítimo. Porque, como nos recordó hace poco Miguel García-Posada, desde su muerte en México en 1955 Moreno Villa siempre ha contado con un pequeño núcleo de lectores y admiradores, quienes han comentado su obra con perspicacia y devoción ${ }^{2}$. También se han hecho constantes esfuerzos por difundir su poesía mediante reediciones y antologías. En este rubro, además de la publicación de dos importantes antologías debidas a Luis Izquierdo y Rosa Romojaro, cabe destacar la edición facsimilar que en 1987 hizo la Residencia de Estudiantes del libro Colección; la reedición que en 1977 promovió la editorial Turner de Jacinta la pelirroja (poema en poemas y dibujos), así como dos reediciones de las Carambas, una anónima y sin fecha, la otra de 1989, debida a la editorial extremeña Norba ${ }^{3}$.

${ }^{1}$ Residencia de Estudiantes-El Colegio de México, Madrid-México, 1998.

2 Miguel García-Posada, "El retorno de un poeta", Babelia, en El País (Madrid), 29 de agosto de 1998, p. 12. Entre otros trabajos importantes publicados a lo largo de los años, cabría destacar el capítulo correspondiente de los Estudios sobre poesía española contemporánea, de Luis Cernuda, Guadarrama, Madrid, 1957; José FranCisco Cirre, La poesía de José Moreno Villa, Ínsula, Madrid, 1963; Eugenio Carmona Mato, José Moreno y los orígenes de las vanguardias artísticas en España (1909-1936), Universidad de Málaga-Colegio de Arquitectos, Málaga, 1985; el catálogo de la exposición José Moreno Villa 1887-1955, ed. Juan Pérez de Ayala, Ministerio de Cultura, Madrid, 1987; y el volumen colectivo que editó Cristóbal Cuevas García, José Moreno Villa en el contexto del 27, Anthropos, Barcelona, 1989.

3 José Moreno Villa, Antología, pról. y sel. Luis Izquierdo, Plaza y Janés, Barcelona, 1982; Antología poética, ed. Rosa Romojaro, Don Quijote-Biblioteca de la Cultura Andaluza, Sevilla, 1993; Colección, Residencia de Estudiantes, Madrid, 1987; Jacinta la pelirroja (poema en poemas y dibujos), con pról. de José Luis Cano, Turner, Madrid, 1977; Carambas, ed. anónima y pirata hecha "por cuenta de unos amantes de la poesía para deleite de sus amigos", Madrid, s. a.; y Carambas, est. introd. de José Luis Bernal, Ediciones Norba 10004, Cáceres, 1989. Para más datos, véase la nutrida bibliografía que acompaña esta ed. de las Poesías completas de Moreno Villa (pp. 821-847). 
Pero aunque la atención prestada a la obra de Moreno Villa ha sido persistente, salta a la vista que no ha logrado atraer para el poeta el reconocimiento del público lector, ni mucho menos de los historiadores de la poesía española contemporánea. Parte de la culpa la tendrán, sin duda, los críticos, que tanta influencia ejercen en el gusto de los demás, porque muchos siguen defendiendo rígidos criterios generacionales que no pueden sino excluir del canon a un poeta como Moreno Villa, quien si bien se acercó tanto a la generación del 98 como a la del 27, finalmente se afirmó como una figura solitaria, libre de toda filiación grupal ${ }^{4}$. Pero también es cierto que la lenta reivindicación de Moreno Villa como poeta se ha visto frustrada -y es importante subrayarlo- por la dificultad para acceder a la mayor parte de su obra. En consonancia con el intento por vincularlo estrechamente a la generación del 27 (vinculación que varios críticos parecen haber asumido como condición sine qua non para la admisión del poeta en la Casa de los Elegidos), el trabajo de reeditar sus obras poéticas se ha centrado hasta ahora en su período vanguardista: Colección, de 1924, Jacinta la pelirroja, de 1929, y las Carambas, de 1931; hecho que, a su vez, ha reforzado la tendencia a concebir a Moreno Villa únicamente como autor de vanguardia. Es decir la dificultad de consultar ejemplares de los otros once libros ha impedido que se consiga una imagen más íntegra y completa de su larga y variadísima trayectoria. La voluminosa obra escrita en el exilio mexicano ha quedado en un olvido lamentable, mientras que la poesía primeriza tampoco se ha leído con frecuencia ${ }^{5}$. Por fortuna, las dificultades

\footnotetext{
${ }^{4}$ El ejemplo más notorio lo ofrece la Historia y crítica de la literatura española que dirige Francisco Rico para la Editorial Crítica de Barcelona. Se trata de una obra de consulta muy útil, elaborada por especialistas en las diversas materias y que por ello ha ejercido una influencia considerable en los medios universitarios. Pues bien, en el t. 7, un grueso volumen de 912 páginas que se ocupa de 1914-1939, no se concede espacio al poeta malagueño. En su Introducción, el coordinador del volumen, Víctor García de la Concha, reconoce que en las páginas sobre los coetáneos de J. R. Jiménez debería figurar José Moreno Villa, "ausente por la obligada constricción de HCLE al estado de la bibliografía” (p. 4). El tomo se publicó en 1984. Diez años más tarde, se editó un Primer suplemento de este volumen (Crítica, Barcelona, 1995, 636 pp.), en donde al malagueño se le conceden, ahora sí, unos cuantos renglones como prosista (p. 369); pero en donde, como poeta, sigue desatendido por completo.

${ }^{5}$ En la bibliografía sobre Moreno Villa se registran, sin embargo, dos tesis que no he podido consultar: Antonia López Frías, La lírica de José Moreno Villa antes del exilio (1913-1936), Universidad de Málaga, 1986; y Ada SALAS, José Moreno Villa (1913-1924), Memoria de Licenciatura, Universidad Complutense, Madrid, 1994. En cuanto al período del exilio, véase, como una de las pocas excepciones a la regla, el interesante estudio de José Amor y VázQuez, "Máscaras mexicanas en Cernuda y Moreno Villa: Quetzalcóatl y Xochipilli”, NRFH, 40 (1992), 1057-1072. Véase también del mismo autor, "Presencia de México en tres escritores españoles: Jarnés, Moreno Villa, Sender", en $\mathrm{CH}(3)$, pp. 77-88.
} 
para conseguir esos textos se terminan con esta edición, imprescindible y largamente anhelada, de las Poesias completas ${ }^{6}$.

Ahora bien, me doy cuenta de que mi voto a favor de esta poesía pide alguna justificación. ¿Qué aporta la obra de Moreno Villa a la poesía española moderna? ¿Qué la singulariza? ¿Por qué es importante leerla? Contestar de manera cabal me llevaría a extenderme demasiado. En lo que sigue, ofrezco tan sólo una serie de breves apuntes, con la esperanza de que dejen vislumbrar las bases de una reivindicación más completa. Para su redacción, he encontrado sumamente útiles y sugerentes las autocríticas del poeta en distintos momentos de su carrera, y que el editor ha tenido el buen tino de colocar al frente de su edición, donde sirven como introducción inmejorable al conjunto. Estas autocríticas (la más temprana se remonta a 1924), establecen un fascinante diálogo que el poeta entabla consigo mismo a la vez que con sus críticos; un diálogo que, dentro de la tradición moderna española, sólo tiene parangón, tal vez, con el conocido "Historial de un libro" que escribió Luis Cernuda en 1958 con motivo de la aparición de la tercera edición de La realidad y el deseo. Aunque el lector, desde luego, no tiene por qué aceptar al pie de la letra todo lo que el poeta afirma, no cabe duda de que estas reflexiones ofrecen numerosas perspectivas desde las cuales enfocar tanto su obra como el lugar especial que ocupa en la historia de la poesía española moderna.

La primera impresión que deja una lectura de los poemas del malagueño tal vez sea la de su insólita heterogeneidad. Como André Gide, Moreno Villa parece haber sido uno de esos autores que se niegan a repetirse, a explotar dos veces un mismo ímpetu creador. Así como cada libro parece producto de una exploración completamente nueva, así también, al pasar de un poema a otro dentro de una misma colección, se observa una constante apertura hacia lo diferente. El poeta estaba orgulloso de este rasgo, que atribuía a un afán de originalidad: "Originalidad de pensamiento o fondo, no de formas [escribió hacia el final de su vida]. En esto ponía mi mayor amor propio. Hasta el punto que si mi nuevo poema se parecía a otro hecho ya por mí, lo rompía” (p. 30). Más que una simple preocupación por distinguirse de los demás poetas de su tiempo (aunque algún prurito de esta especie pudo haberlo motivado también), se trataba, por lo visto, de un deseo sobre todo de permanecer fiel a los auténticos impulsos de su experiencia: "Para mí la poesía es un perpetuo descubrimiento hacia el cual me disparo [escribió, por ejemplo, en 1924].

\footnotetext{
${ }^{6}$ A partir de este momento, gracias a los esfuerzos del editor Juan Pérez de Ayala, pero también gracias al generoso patrocinio de la Residencia de Estudiantes y de El Colegio de México (instituciones apoyadas a su vez por la Agencia Española de Cooperación Internacional y por el Fondo Eulalio Ferrer), la excepcional carrera del poeta va a poder seguirse y estudiarse en toda su complejidad.
} 
Ayer -más que hoy-, me disparaba frenético, y por esto, a veces, quedaban en la trayectoria oscuridades y confusiones. He sido siempre, por naturaleza, más bien 'fáustico' que 'apolíneo', si vale la terminología de Spengler" (p. 3).

Este empeño por respetar los movimientos "fáusticos" del instinto poético da pie no sólo a las ocasionales oscuridades y confusiones a las que el poeta alude, sino también a los inquietantes quiebros que se perciben una y otra vez en el ritmo de sus versos; quiebros que resultan desconcertantes, sobre todo para lectores acostumbrados a una musicalidad más previsible y más convencional. Por estos rasgos, algunos llegan a considerarlo un poeta descuidado o incluso a insinuar que le faltaba el oído necesario para distinguir el ritmo de la poesía, a lo cual Moreno Villa seguramente habría contestado que no era descuidado ni insensible al ritmo, que las posibilidades rítmicas de la poesía eran infinitas y que si la cadencia de sus versos resultaba a menudo desconcertante y paradójica, se debía a que la visión poética a la que procuraba dar expresión también lo era. Y es que la poesía de Moreno Villa es de inestabilidades, de intuiciones fluctuantes y proteicas, de tensiones no resueltas, en la que lo importante es la energía de la búsqueda, más que la claridad y armonía de la línea que esta búsqueda va dejando tras sí.

Sería inútil, por lo tanto, buscar en la obra de Moreno Villa esa construcción (rítmica y temática) clásicamente armoniosa que encontramos en otros poetas de su tiempo. Pongamos como ejemplo el caso de Jorge Guillén, que en cierto modo es la antípoda del malagueño. Moreno Villa parece haber admirado mucho a Guillén; sin embargo, con no poca pena se daba cuenta del abismo que lo separaba de su amigo: "Guillén vive en la utopía de un mundo que vislumbró una mañana divina y nos lo quiere imponer como único y permanente. $\mathrm{Su}$ vida es idea, concepto, más que vida verdadera. Y así su substancia poética adolece de entelequia. Es un esqueleto tan racional y seco como un silogismo; aunque lo adorne con intuiciones frescas acá y allá, se nota el andamiaje, el artificio” (p. 62). En efecto, nada más lejos de la poesía de Moreno Villa que esa "fe de vida", ese asombro ante la plena y luminosa presencia de las cosas que se afirma en Cántico. Y de ahí también las disonancias e irregularidades, los inesperados vaivenes, que distinguen su obra de la de Guillén.

Pero ¿en qué consiste, más precisamente, la visión de Moreno Villa? El tema ha sido objeto, hace poco, de un extenso y profundo estudio del crítico Humberto Huergo, quien en el transcurso de un análisis de Jacinta la pelirroja, relacionó al malagueño con una línea metafísica que, inaugurada por el Barroco, fue asimilada, recreada y difundida por los románticos alemanes, hasta convertirse, con el paso de los años, en la corriente central del arte moderno. "El arte del siglo xx - afirma Huergo- no buscaría tanto la representación posi- 
tiva de una forma visible, cargada de un sentido familiar placentero, cuanto la representación negativa de una «nada viva»...; la pintura de un «hueco», pero "vivo»"7. Sería muy difícil resumir aquí la larga y sugerente tesis de este crítico, pero creo que el oxímoron de la "nada viva" (imagen tomada, por cierto, de uno de los poemas de Moreno Villa) servirá para dar una idea del carácter complejo e incluso paradójico de la visión del poeta. El poeta contempla el mundo de los fenómenos inmediatos, pero, a diferencia de lo que ocurre en el mundo de Cántico, por ejemplo, donde el ser irradia su presencia, en la poesía de Moreno Villa el mundo elude una percepción racional o completa: es un fantasma que se ve y a la vez no se ve; fenómeno éste que sólo puede expresarse, si es que expresarse puede, mediante las paradojas de un pensamiento que se ve obligado a contradecirse, a retractarse y a corregirse; desde el momento en que el poeta pretende formular la intuición, la necesidad de negarla se le impone como exigencia de la creación. "Es lo de todos los grandes...", escribió Moreno Villa en 1925. "El 'sí, pero no', seguro indicio de que hay un mañana, algo que no ha nacido todavía, algo que quiere valerse de uno para salir"8. El mundo se revela ante el poeta, sí, pero sólo a fuerza de estar a la vez ausente.

Por lo visto, esta experiencia contradictoria fue la que Moreno Villa intentó explicar en la "Poética" que escribió para la famosa Antología de Gerardo Diego:

El fenómeno poético es un estado de gracia. No sé cómo poder dibujarlo con la pluma. Yo sé que me desligo totalmente de lo circundante y que penetro en una zona luminosa y sorda, donde la situación de mi ánimo o la intención inicial que traía al penetrar en ella va cuajando o expresándose gracias a la baraja de posibilidades, recuerdos, asociaciones de la fantasía. En aquella zona mandan mucho los contrarios: la luz y la sombra, la ironía y la gravedad, la fe y la incredulidad, la pena y la alegría. Son los que dan claroscuro (pp. 8-9).

A un lector incauto tal vez se le ocurriría ver cierto parecido entre esta poética y la técnica de asociaciones libres promulgada por los surrealistas. Sin embargo, se trata de dos experiencias muy distintas. En realidad, no hay nada libre en las asociaciones desarrolladas por Moreno Villa. Todo gira alrededor de esa angustiosa perplejidad, esa

7 "Lo sublime y la vanguardia. Forma y finalidad en Jacinta la pelirroja", NRFH, 44 (1996), 489-540. La cita se encuentra en la p. 497. Como complemento de este estudio de la poética de Moreno Villa, resulta muy instructivo lo que sobre la obra pictórica del malagueño dice HuErgo en su prólogo, "El testigo de lo otro", al catálogo José Moreno Villa. Óleos, dibujos, grabados, grafumos y un alambre, ed. Juan Pérez de Ayala, Galería Guillermo de Osma, Madrid, 1999, pp. 9-39.

8 "Cézanne y el Greco: arrebato y ley", El Sol (Madrid), 26 septiembre 1925; apud Huergo, art. cit., p. 502. 
herida en el ser que proviene de la percepción del doble fondo ( $\sin$ fondo) que es el mundo para el poeta. Más que un divertimiento arbitrario, más incluso que una liberación, la poesía para Moreno Villa es una visión y una ascesis. "La noche abrió en mi fondo innúmeras pupilas; / vi que era misteriosa la más ingenua vida”, escribió Moreno Villa en uno de sus poemarios más tempranos, "En la selva fervorosa” (p. 161). El poeta percibe de repente el misterio del mundo, pero en el mismo momento, como señala en otro poema de este ciclo, también descubre "el terror milenario del vacío" (p. 151).

Una vez iniciado en este rito, el poeta no puede dejar de percibir el borde oscuro de las cosas: la presencia latente de seres que se asoman, que buscan nacer, por un lado, pero también, por otro, el latido del tiempo, la sombra de muerte sobre la cual se levanta, cada vez con mayor dificultad, toda forma aparentemente viva. Se trata, en fin, de una percepción que aísla al poeta a la vez que lo deja sin arraigo en el mundo; una experiencia que, en cuanto necesita expresarse y comunicarse, también lo impulsa por el camino del sacrificio:

No hay que esperar socorro del hermano;
suspenso estoy en el vacío, y tengo
para asirme que asirme a los espacios.
...
Solo en la selva del dolor estoy.
Ya tengo brazos en el firmamento.
¡Ya mi raíz parece que ha llegado
a la región del sacrosanto fuego!

(pp. 153-154).

Poesía y soledad. El alma del poeta como crisol en el cual la constante transformación de las cosas se lleva a cabo. El poeta que sufre y se sacrifica para que el misterio del mundo encuentre su expresión más pura, más definitiva. La poesía como ascesis y como destino. En obras posteriores Moreno Villa amortiguará la nota de autocomplacencia que se observa en estos versos primerizos, insistiendo más bien en un tono irónico y de good sport, sin embargo, no creo exagerado decir que esa concepción romántica de la poesía es la que caracteriza su obra a lo largo de su carrera. Diría también que, más que su interés por el movimiento surrealista, fue la presencia en su obra de este romanticismo (un romanticismo metafísico fuertemente imbuido, hay que señalarlo, de elementos tomados de la poesía popular andaluza) lo que hizo que los poetas del 27 se acercaran a él como a un espíritu afín; lo que hizo, por ejemplo, que en 1931 Luis Cernuda identificara el inicio de la poesía española moderna con la publicación en 1913 de la primera obra de Moreno Villa, Garba ${ }^{9}$.

${ }^{9}$ La opinión de Cernuda fue tajante: "Esa poesía, pues, a la que actualmente se 
En las autocríticas escritas al final de su vida, Moreno Villa no se mostró muy seguro de la importancia de su obra para los poetas más jóvenes, aunque se dio cuenta de que sí había ejercido alguna influencia: "Que me leyeron García Lorca y mis paisanos Prados y Altolaguirre, me consta, pero todos tuvieron su voz propia... Si alguno de éstos quisiera hablar claro terciando en esta cuestión, podría hacer un servicio a la verdad histórica. De todos ellos, el que aportaría conceptos más esclarecedores sería el pobre Federico. Él aquilataba lo nuevo mío en cada libro, me escribía desde Granada con particular entusiasmo y me consta que agrupaba a sus amigos para leerles mi Pasajero, mi Luchas de Pena y Alegría, mi Jacinta la pelirroja y los siguientes libros" (pp. 32, 41) ${ }^{10}$.

Mi hipótesis es que, más allá de naturales afinidades de cultura andaluza, lo que descubrieron estos jóvenes poetas en la obra de Moreno Villa fue el concepto religioso o "sacrificial" de la poesía que acabo de delinear: la noción de que el poeta tiene que inmolarse, entregarse a la vía negativa, para que las formas ocultas (y no tan ocultas) de la vida nazcan, para que la vida prosiga su proteico camino a través de sus versos. Como prueba de ello, ahí está la historia de "nacimientos" de Emilio Prados o su "misterio del agua"; o también el "Nocturno del hueco" de Lorca, o en un sentido más general su identificación del acto creador con el sufrimiento amoroso de Cristo o con el martirio de san Sebastián. ¿Influencia del poeta mayor en la obra de los poetas más jóvenes? ¿O lecturas paralelas de una fuente común? ¿ O ambas cosas a la vez? Es difícil saberlo. En todo caso, creo que este romanticismo de lo sublime ocupa un lugar central en la poesía española moderna y que Moreno Villa constituye uno de sus practicantes más fieles.

designa como «moderna poesía española», aparece en 1913 con José Moreno Villa. No insistamos ahora en cuál sea esa poesía, en qué medida merezca tal nombre y en cuáles sean sus límites. Sólo indicar ese hecho de que Garba inicia y separa". Véase Luis Cernuda, "José Moreno Villa o los andaluces en España", El Sol (Madrid), 18 de enero de 1931; recogido en su Obra completa, t. 3: Prosa II, eds. Derek Harris y Luis Maristany, Siruela, Madrid, 1994, p. 25. Esta reivindicación de la poesía del malagueño seguramente fue escrita como airada respuesta a la determinación inicial de Gerardo Diego - determinación anunciada por carta- de dejar fuera de su famosa Antología tanto a Moreno Villa como a Emilio Prados; si Diego luego revocó su decisión, seguramente fue en parte debido a esta protesta. Para más datos sobre dicho episodio, véase el documentado estudio de Gabriele Morelli, Historia y recepción de la "Antología" poética de Gerardo Diego, Pre-Textos, Valencia, 1998.

10 La temprana influencia de Moreno Villa en Lorca fue señalada por Luis CERNUDA en sus Estudios sobre poesía española contemporánea; véase su Obra completa, t. 2: Prosa I, eds. Derek Harris y Luis Maristany, Siruela, Madrid, 1994, pp. 165-166. Tras la muerte de Moreno Villa, tanto Prados como Altolaguirre publicaron tributos póeticos a su memoria: el primero, "En tu selva fervorosa. A Pepe Moreno, en mi memoria de siempre", Las Españas (México), julio de 1956, núms. 26/28, p. 9; y el segundo, "Tres poemas a José Moreno Villa", México en la Cultura, suplemento de Novedades (México), 19 de junio de 1955, núm. 362, p. 3. 
Ahora bien, como todos sabemos, el romanticismo fue un movimiento muy rico y variado, y es una de las pruebas de la riqueza y variedad de la poesía de Moreno Villa el que haya asimilado no sólo el lado sublime o metafísico del romanticismo alemán, sino también esa otra expresión complementaria que era la ironía romántica. Para explicar este otro lado de la poesía del malagueño, tal vez convendría referirnos a su crítica literaria, y concretamente a uno de los libros que publicó en su exilio mexicano: Los autores como actores y otros intereses de acá y de allá ${ }^{11}$.

El tema está implícito, de alguna manera, en la frase que sirve como título, tanto de la primera sección como del libro en su conjunto: "Los autores como actores". Al leer, se ve una y otra vez la fascinación que Moreno Villa siente por la relación que existe, o que puede existir, entre el escritor y la imagen de sí que proyecta en su obra. Si bien en otras ocasiones cede a la tentación de confundir los dos términos, de identificar de manera absoluta el hombre con su obra, aquí su actitud es más matizada, más sutil: reconoce que la experiencia de un escritor nunca se expresa directamente, sino a través de un lenguaje que transforma la materia prima en obra de arte. El escritor, al expresarse, se interpreta y se recrea -se dramatiza- de modo que entre un poeta (por ejemplo) y su imagen poética se da la misma relación que entre el actor y el papel que éste interpreta: el autor termina siendo actor de sí mismo.

Según creo, es esta misma capacidad de distinguir entre las dos caras de su identidad - entre la personalidad literaria y la personalidad humana- la que constituye el otro rasgo más saliente del trabajo de Moreno Villa como poeta. En efecto, los mejores poemas de Moreno Villa se desarrollan en forma de diálogo entre estas dos voces de su conciencia. La voz literaria busca expresarse a través del ritmo exaltado típico de la gran tradición romántica, pero en seguida interviene la voz humana para quebrar el ritmo y así arraigar el poema dentro de una experiencia más concreta (es decir repleta de impulsos contradictorios). De ahí no sólo la ironía, el humor, sino también el prosaísmo del que suelen hablar los comentaristas de su obra. Y es que, como explica Moreno Villa en "Cartas sin correo", uno de los poemas recogidos en la colección póstuma Voz en vuelo a su cuna (1961):
Nuestra pereza letal y divina
quiere sentirse llevada en las ondas.
La pereza es el ritmo telúrico, que preside a la piedra del monte, a la flor y al torrente.

${ }^{11}$ El Colegio de México, México, 1951. Retomo a continuación algunas de las ideas expresadas en mi nota sobre "Moreno Villa, crítico literario", Vuelta, junio de 1987, núm. 127. 
Pero hay que romper el compás

cada vez que tú quieras más

(p. 656).

Fue Octavio Paz quien, en varias ocasiones, celebró la presencia del coloquialismo en poemarios de Moreno Villa como Jacinta la pelirroja (1929) y Carambas (1931) ${ }^{12}$. Sin embargo creo que no se ha apreciado debidamente la forma en que el prosaísmo de este poeta, rebasando simples cuestiones de dicción poética, llegó a formar parte de una propuesta mucho más compleja, que suponía la dramatización irónica de su persona, un procedimiento que, aunque presente en libros anteriores, resulta especialmente feliz en colecciones como Puentes que no acaban (1933) y Salón sin muros (1936). De este último cabe destacar el poema cuyo título sirve para identificar al conjunto; un poema en que, partiendo de unos versos conocidos de Campoamor $^{13}$, el poeta elabora un penetrante autorretrato en forma de monólogo dramático:

"Las hijas de las madres que amé tanto"

me festejan, me impulsan al baile, me alborotan los pelillos grises de la mollera y me miran como a un imposible padre-soltero, como a cosa que se ve y no se cree.

Como indica el último verso, el poeta sigue concibiendo la realidad como un fantasma; como algo que "se ve y no se cree"; aunque ahora lo fantasmal lo constituye, no el mundo exterior, sino el poeta mismo. Y conforme avanza el poema, la ironía se va agudizando:

12 En conversación con Julián Ríos, por ejemplo, Paz afirmó lo siguiente: "Habría que colocar a Moreno Villa en el sitio que verdaderamente le corresponde: es el primero que intentó (y logró) escribir poesía coloquial. De verdad coloquial y poesía de verdad" (Solo a dos voces, Lumen, Barcelona, 1973, s. p.). En 1964, en el transcurso de un ensayo sobre Cernuda, PAz había sido aún más explícito al respecto: "Cernuda vio en Campoamor un antecedente del prosaísmo poético; si lo fuese, sería un antecedente lamentable. No hay que confundir la charla filosófica de sobremesa con la poesía. La verdad es que el único poeta español moderno que ha usado con naturalidad el lenguaje hablado es el olvidado Moreno Villa. (El único y el primero: Jacinta la pelirroja se publicó en 1929)" ("La palabra edificante", Obras completas, t. 3: Fundación y disidencia. Dominio hispánico, Círculo de Lectores-F.C.E., México, 1994, p. 246). En este volumen se recogen varios comentarios más sobre este "excelente poeta inexplicablemente olvidado por sus compatriotas" (p. 98) que fue, para Paz, José Moreno Villa.

${ }^{13}$ La breve humorada de CAmpoAmor (antecedente tal vez no tan "lamentable" como Paz nos quiso hacer creer) reza como sigue: "Las hijas de las madres que amé tanto,/ me besan ya como se besa a un santo" (véase Antología poética, ed. Víctor Montolí, Cátedra, Madrid, 1996, p. 427). 
Mi celibato me permite comer acá y allá, concluir el mes con el último céntimo y tener en suma cierta levedad juvenil.

Pero, como de cierto, ya tengo cuarenta y nueve

[navidades,

mi ser y mi modo de ser son un poco raros.

Y las hijas de las madres que adoré un día

me miran y tocan para comprobar mi existencia.

Lo mismo, exactamente lo mismo que yo.

A veces, me sorprende oír que un amigo

recuerda frases y gestos míos,

juicios remotos sobre cosas que ya olvidé.

Me sorprende que existan rastros

de un ser cuya existencia no alcanzo,

de un ser ingrávido, invisible,

soplo de sombra en noche cerrada

que es la imagen que de mí tengo...

(pp. 413-414)

Si bien hay que relacionar a Moreno Villa con el romanticismo sublime, también practicado por algunos de los poetas del 27, con igual derecho se lo podría identificar con la larga tradición de la "poesía de la experiencia” que, remontando, en lengua española, a Espronceda y a Manuel Machado (dos poetas muy admirados por el malagueño) y pasando por Luis Cernuda, desemboca en la obra de Jaime Gil de Biedma y de sus discípulos.

Aunque los rasgos que acabo de señalar se mantienen a lo largo de la carrera del poeta, no puedo terminar sin recomendar de manera muy especial los poemas escritos en el exilio mexicano, que, sin renunciar a las temáticas anteriores, se enriquecen de perspectivas nuevas, dolorosamente impuestas por las circunstancias. A la angustiante vivencia del desarraigo ontológico o metafísico se le agrega, a partir de 1937, la dura experiencia del destierro histórico; ruptura que el poeta tal vez sólo pudo superar gracias a una extraña fe en el sentido misterioso del destino individual, que el inesperado nacimiento de un hijo en 1940 vino a confirmar. En efecto, por muy sorprendente que resulte, la paternidad es el tema de la mayoría de los poemas incluidos en sus dos primeros libros escritos en el exilio: Puerta severa (1941) y La noche del Verbo (1942) ${ }^{14}$. Y es que, partiendo

14 Sobre La noche del Verbo, véase el lúcido comentario de Octavio Paz, "Absurdo y misterio", Obras completas, t. 13: Miscelánea I. Primeros escritos, Círculo de Lectores-F.C.E., México, 1999, pp. 299-302. 
de una identificación del nacimiento de su hijo con el Nacimiento de Cristo ("paternidad nos lleva a cristiandad"), el poeta descubre en esta "estrella rosa de la noche" una presencia que niega la destrucción y el sufrimiento presentes en el mundo, que reconcilia al hombre con su destino, restituyendo así cierto sentido a la vida:

\author{
¿Qué viraje sufrió la humanidad \\ para ver en el niño \\ el centro de la vida? \\ Del terror al amor: así fue el cambio. \\ Déjame noche negra y pensadora \\ derramar mi alegría como llanto \\ delante de este amor que es lo indefenso, \\ lo puro y lo vivaz, lo que en su día \\ vuelve a crear el Verbo
}

(pp. 465-466).

La guerra civil obligó a Moreno Villa a estrenar vida nueva en México, a los 50 años. Exigencia difícil, para el poeta no menos que para el hombre, porque, como recordaría en 1949 en el transcurso de una lectura de sus poemas ofrecida en el Ateneo Español de México, el destierro significó algo más que la simple pérdida de caras amigables y de paisajes conocidos: "La pérdida significó mucho: fue quedarnos sin suelo; fue quedarnos en el aire; pero fue más, fue sentir quebrada e interrumpida la trayectoria natural; fue desviarnos y empujarnos hacia metas imprevistas”. Y todo esto, además, en un momento, por lo menos en su caso, "cuando ya las fuerzas juveniles estaban en crisis y muchas de las creencias o ideales" (p. 14). Es sintomático del temple moral de Moreno Villa que estuviera a la altura de estas difíciles circunstancias. En los últimos dieciocho años de su vida, en una obra poética cuyo perfil apenas ahora se puede empezar a percibir en toda su extensión, el poeta se puso a explorar la nueva realidad en que vivía, a la vez que emprendió una larga meditación sobre el sentido del naufragio, sobre el desaliento personal y colectivo, sobre la incomprensión con que muchas veces era recibido en el mundo nuevo (a pesar de las buenas intenciones de unos y de otros), sobre el paso del tiempo, sobre la muerte... Nos legó así algunos de los poemas más bellos y más conmovedores de los muchos escritos por los exiliados. Pienso, por ejemplo, en "iPorteros!”, "Confusión y bloqueo", "Nos trajeron las ondas" o "Canciones a Xochipilli". Aunque frente a estos poemas extensos, algunos podrían sentir preferencia más bien por sus poemas breves, en los que el lirismo resulta más intenso. Por un poema como "Oigo", por ejemplo, en que, con mínimos recursos, Moreno Villa evoca ese drama, doblemente doloroso para el desterrado, que era el paso del tiempo: 
A veces oigo los pétalos de la rosa dando en tierra; tan tirante es el silencio; tan en aviso está el alma.

A veces oigo la fuga de la luna en su viraje; tan grande es la soledad; tan tenso vive el espíritu.
A veces oigo la arena del Tiempo caer en mí; me levanto, me paseo, toco la estampa o el libro, miro la luz de la lámpara, me froto las tibias manos y me siento lentamente a ver cómo la de arriba está casi toda abajo

(pp. 481-482).

Como habrá comprobado en seguida cualquiera que haya tenido esta edición en sus manos, se trata de un libro editado con sumo esmero. Entre otros aspectos cabría destacar el rescate fiel de los dibujos que acompañaban los poemas originales del poeta Moreno Villa, así como la cuidadosa reproducción a color de una selección de los cuadros del pintor Moreno Villa, rasgos que hacen del volumen una verdadera delicia para la vista. Estos detalles se los debemos al editor, Juan Pérez de Ayala, quien con ellos ha querido subrayar (y con mucha razón) las profundas interrelaciones que existen entre la obra poética del malagueño y su obra pictórica. También contribuye de manera notable a dar una fisonomía muy grata al libro el trabajo tipográfico, que ha corrido a cargo de uno de los últimos representantes de la gran escuela tipográfica que creara en México el exilio español: Martí Soler. Si un manuscrito tan extenso, y de estructura tan compleja, como el que preparó Juan Pérez de Ayala, se convirtió en un libro tan esbelto y tan finamente ordenado, esto se debe no poco a la destreza y dedicación con las que Martí Soler, explotando los más diversos recursos tipográficos, trazó la forma y el sentido del conjunto.

Pero las virtudes no corresponden únicamente a la forma externa del libro. La edición también destaca por sus atributos (digamos) críticos o filológicos. Al logro nada desdeñable de haber reunido por primera vez todos los libros de poesía que Moreno Villa publicara en vida $^{15}$, se suma la de haber rescatado a la vez unos 145 poemas suel-

15 En el caso del libro Evoluciones (Biblioteca Calleja, Madrid, 1918), un volumen que junta ensayos con poemas tanto en prosa ("Bestiario") como en verso ("Epitafios"), el editor decidió sólo rescatar estos últimos; y eso, a pesar de que, según Moreno Villa, los poemas en verso "iban estrechamente unidos a los «retratos» del Bestiario" (p. 6). La decisión tal vez fuera tomada por razones de espacio. Sin embargo, al quedar fuera los poemas en prosa, no cabe duda de que se pasa por alto un aspecto muy interesante de la creación poética de Moreno Villa y uno que llegó a tener importantes repercusiones en la obra de otros poetas; pienso, por ejemplo, en las "caricaturas líricas” que J. R. Jiménez empezó a escribir a principios de la década de 1920 y que luego editaría bajo el título de Españoles de tres mundos (1942); o también en el libro de Caracteres que José Bergamín publicara en 1927. Según Mario Hernández, a 
tos, más otros sesenta inéditos, la mayor parte de ellos escritos en el exilio mexicano. La edición de los poemas, hasta donde puedo juzgar, es cuidadosa. No se trata de una edición crítica exhaustiva, pero falta poco para que pueda considerarse como tal. En las notas se recogen las principales variantes léxicas que ofrecen los poemas, basadas éstas en un cotejo minucioso no sólo de las distintas versiones publicadas en libros y revistas, sino también de las versiones inéditas que constan en los numerosos cuadernos y manuscritos conservados en el Archivo José Moreno Villa de la Residencia de Estudiantes. Una proporción muy grande de estos manuscritos y cuadernos, hay que señalarlo, tiene que ver con la antología de su obra que el poeta preparó en México y que finalmente publicó en 1949 bajo el título de La música que llevaba. Los datos precisos y bien documentados que Juan Pérez de Ayala nos proporciona en las notas a su edición, tienen, entre otras muchas virtudes, la de permitirnos apreciar el alcance de la rigurosa relectura de toda su obra que el poeta entonces realizara con vista a dicha antología.

En fin, se trata de una edición de las Poesías completas que Moreno Villa hubiera contemplado, estoy seguro, con profunda satisfacción; aunque, a lo mejor, con un poco de tristeza también, al ver cómo una obra vasta y variada como la suya, siempre abierta al tiempo, finalmente se encerrara entre las pastas duras (y destemporalizantes) de un libro. Porque, como dice en su poema "La cara completa", al escribirlos lo que menos quería era sacrificar el latir multiforme de la vida a la formulación de una sola imagen intemporal:

Como la cara no se termina hasta la muerte, no te preocupes tanto del espejo.

Mira más bien, cómo debes tratar a la fiera, con qué pulso tomarás la pluma,

con qué cuidado juzgarás de la flor.

Cuando se termine tu cara,

tendrás en ella tu vida,

tu vida y tu muerte.

quien debemos la reedición de una pequeña muestra del Bestiario, este proyecto de Moreno Villa tiene como antecedente inmediato Le bestiaire ou cortège d'Orphée, de Apollinaire (1911): “¿Conocía Moreno Villa ese libro cuando imaginó las figuras del faisán, el antílope o el cisne? Concibe Apollinaire sus estrofas como un divertimento que aúna ingenio y lirismo; estos más sueltos esbozos poemáticos del español son ajenos a aquella aguda concentración - de la que sí debió gustar Valle-Inclán para su «Bestiario» de La pipa de Kif (1919) - y buscan una gracia de otra estirpe, más atenta a lo social y solidario que al juego subjetivo" ("Fábula de Moreno Villa", pról. a Bestiario, Ultismo, Madrid, 1985, p. 8). Para un estudio de las relaciones de esta obra con la tradición fabulística, veáse EduARdo JiméNez URdiales, "Claves de inspiración popular: el «Bestiario»", La narrativa de José Moreno Villa: "Evoluciones" y "Patrañas", Centro de la Generación del 27, Málaga, 1998, pp. 81-105. 
Ella entonces será tu retrato, el retrato de los ojos cerrados, que no sonríen ni prometen ni se desesperan ni mienten. El retrato de la nariz perfilada, el retrato de la boca cerrada, el retrato de la faz serena, de la frente ancha, donde quedaron para siempre todos los horizontes recorridos, y todos los secretos despejados. Retrato de los surcos dolientes y de las canas desengañadas, de la nariz que ya no aspira, y de la garganta que no traga. Retrato, en suma, terminado. Sin mutaciones de color, insensible a los cambios del tiempo

(pp. 521-522).

Esta cara completa es el conmovedor retrato de Moreno Villa, redivivo, que nos ofrece la presente edición. Ojalá que los próximos rescates auspiciados por la Residencia de Estudiantes y El Colegio de México resulten tan hermosos como éste.

JAMES VALENDER

El Colegio de México 